Research Paper

\title{
Salmonelloses in the State of Rio Grande do Sul, southern Brazil, 2002 to 2004
}

\author{
Vanessa Rech Wagner ${ }^{1}$, Josete Baialardi Silveira ${ }^{2}$, Eduardo Cesar Tondo ${ }^{1}$ \\ ${ }^{1}$ Instituto de Ciência e Tecnologia de Alimentos, Universidade Federal do Rio Grande do Sul, \\ Porto Alegre, RS, Brazil. \\ ${ }^{2}$ Setor de Alimentos, Divisão de Vigilância Sanitária, Centro Estadual de Vigilância em Saúde, \\ Porto Alegre, RS, Brazil.
}

Submitted: December 1, 2011; Approved: September 10, 2012.

\begin{abstract}
Salmonella has been identified as the main aetiological agent responsible for foodborne diseases in several countries worldwide, including Brazil. In the State of Rio Grande do Sul (RS), southern Brazil, previews studies analysed official foodborne illnesses data, identifying Salmonella as the main bacterial agent of foodborne diseases during the period of 1997 to 2001. The present study aimed to analyse the official epidemiological data on salmonelloses occurred in the State of RS, during the period of 2002 to 2004. Even though data on recent salmonelloses were available, only data concerning the period comprising in 2002 to 2004 were analysed because the official worksheet records presented more consistent information about the salmonellosis outbreaks. Results indicated that, among the 624 foodborne outbreaks officially investigated, 202 (32.37\%) were confirmed as salmonellosis. Among them 23,725 people were involved, 4,148 became sick, 1,878 were hospitalized and one person died. The season with the highest incidence of salmonelloses was spring, and the most affected age group was composed of people aged between 20 to 49 years old (56.66\%). Animal origin foods - especially eggs and meat products - were very often involved with the outbreaks, however homemade mayonnaise was identified as the main food vehicle for salmonelloses (53.51\%). The majority of the cases occurred inside private homes (55.81\%) and food services $(12.1 \%)$, and the main factors contributing to the occurrence of the outbreaks were the consumption of products without sanitary inspection $(26.7 \%)$ and exposure of food at room temperature for more than two hours (18.58\%). Similarly to what was previously reported for the period of 1997 to 2001, Salmonella spp. was the most prevalent foodborne disease agent in the State of RS during the years of 2002 to 2004.
\end{abstract}

Key words: Salmonelloses, Brazil, The State of Rio Grande do Sul.

\section{Introduction}

Salmonella has been reported as an important cause of concern in the contemporary world. Global surveillance data has indicated that the number of salmonelloses has increased expressively during the last years, mainly associated with the consumption of raw or undercooked eggs, poultry, meat or dairy products (Brasil, 2010; Caffer and Eiguer, 2004; Laconha et al., 2000; Mead et al., 1999; Notermans and Hoogenboom-Verdegaal, 1992; Peresi et al., 1998; Roadford and Board, 1993; Scallan et al., 2011; Lindqvist et al., 2000; Tondo and Ritter, 2012).
During the last decade, salmonellosis has been reported as the most frequent foodborne disease in Brazil, and animal products have been identified as the most frequent food vehicles responsible for such syndromes (Brasil, 2010). Since Brazil is currently the biggest exporter of poultry and red meat in the world, the control of Salmonella is of great interest in this country.

In RS, the southernmost State of Brazil, there are many well developed industries for producing poultry, pork and red meat, in which great efforts are made to control Salmonella. However, Salmonella has been identified as the main cause of foodborne diseases investigated by regula-

Send correspondence to: E.C. Tondo. Instituto de Ciência e Tecnologia de Alimentos, Universidade Federal do Rio Grande do Sul, (ICTA/UFRGS), Porto Alegre, RS, Brasil. E-mail: tondo@ufrgs.br. 
tory bodies since 1997 (Brasil, 2010; Mürmann et al., 2008; Oliveira et al., 2007; Rio Grande do Sul, 2001), occurring mainly in private homes and food services.

Aiming to understand the characteristics and causes of salmonellosis outbreaks in the State of RS, improved surveillance services and reporting of outbreaks are constantly necessary, thus making it possible to set priorities and implement preventive measures in order to reduce the occurrence of these illnesses (Costalunga and Tondo, 2002).

The foodborne outbreak investigations began in the State of RS in 1980, making it possible to identify locals where illnesses occurred, food vehicles and other factors related with foodborne diseases (Rio Grande do Sul, 2001). The foodborne epidemiological investigation in RS is a result of the collaborative work of the Division of Epidemiological Surveillance, Division of Sanitary Surveillance (DVS/RS) and Central Public Health Laboratory of the State of RS (FEPPS/LACEN/RS), all bodies coordinated by the Secretary of Health of the State of RS. The structure of this regulatory body in RS is composed of nineteen Regional Health Coordination sectors which work in cooperation with the municipalities, investigating foodborne diseases occurred in a population of more than 10.7 million people (Carmo et al., 2005, Rio Grande do Sul, 2001). Foodborne outbreak investigations start after the regulation bodies are informed, and this generally occurs after larger outbreaks. Whenever possible, sanitary officers collect the suspected foods and send it to be analysed in the Central Public Health Laboratory (FEPPS/LACEN/RS) or in other accredited laboratory close to the site of the outbreak occurrence (Brasil, 2001). However, in many salmonellosis outbreaks it is not possible to collect food samples because the suspected food was either totally consumed or purposely removed (Costalunga and Tondo, 2002, Rio Grande do Sul, 2001). For this reason, many salmonellosis outbreaks are investigated and concluded based on the epidemiological and clinical data registered on the official worksheets (Brasil 2001, Carmo et al., 2005), thus demonstrating the importance of outbreak records. However, this information is not always accessible and it can be better publicized if official data are analysed and published on scientific manuscripts.

The present scientific report is a result of the collaborative work of the Food Science and Technology Institute of Federal University of Rio Grande do Sul (ICTA/UFRGS) and the Secretary of Health of RS, whose aim was to disseminate relevant information about the investigation of salmonellosis carried out in the State of RS. The objective of this work is analysing the official registered data of salmonellosis outbreaks occurred in the State of RS, during the period of 2002 to 2004.

\section{Materials and Methods}

Epidemiological data on salmonellosis outbreaks occurred in the State of RS, Brazil, during the period of 2002 to 2004 , were analysed by using the database registered on worksheets of epidemiological investigation conducted by Secretary of Health of RS. The final reports were done by the Division of Epidemiological Surveillance, while the investigations of the outbreaks were carried out by the Sanitary Surveillance services of the State of RS and municipalities. Only epidemiological data on salmonelloses occurred between 2002 to 2004 were chosen and analysed for two reasons: 1) to give sequence of previous epidemiological studies about salmonelloses of RS concerning the period of 1997 to 1999 (Costalunga and Tondo, 2002) and 2000 to 2001 (Silveira and Tondo, 2006); 2) data available on the official worksheet records of 2002 to 2004 presented consistent and detailed information about the salmonellosis outbreaks, make it possible this publication.

The data analysis focused on evaluating the following information: number of involved people, age and sex of real patients, number of deaths, most probable causes for the outbreaks, place of consumption (intake), food vehicles, and period of the year when the salmonelloses occurred.

When possible, inspectors of the Sanitary Surveillance Services of the municipalities collected samples of suspect food, feces of sick people and swab samples of food handlers. These samples were microbiologically analysed using methods described by the Food and Drug Administration in The Central Laboratory of Rio Grande do Sul (FEPPS/LACEN/RS), or other accredited laboratories in different regions of RS. Available microbiological results were also investigated in the present study.

\section{Results}

In the period between 2002 and 2004, 624 investigated outbreaks were recorded in Secretary of Health of the State of RS. Among them, 202 outbreaks (32.37\%) were caused by Salmonella spp. In these outbreaks, 23,725 people were involved, 4,148 became ill, 1,878 were hospitalized and one person died (Table 1).

Results showed in Figure 1 demonstrates that springtime (October, November and December) had the highest incidence of salmonellosis in the State of RS $(n=14)$, while summertime (January, February and March) proved to have the second greatest rate of salmonellosis occurrence $(n=9)$.

The aging group most affected was adults ageing 20 to 49 years old $(56.66 \%$ ), followed by children and teenag-

Table 1 - General data about outbreaks of Salmonella spp. in the State of Rio Grande do Sul, Brazil, 2002 to 2004.

\begin{tabular}{lcccc}
\hline & 2002 & 2003 & 2004 & Total \\
\hline Confirmed outbreaks & 89 & 57 & 56 & 202 \\
Involved people & 6504 & 13810 & 3438 & 23752 \\
Ill people & 1649 & 1510 & 989 & 4148 \\
Hospitalized people & 812 & 713 & 313 & 1838 \\
Deaths & 1 & 0 & 0 & 1 \\
\hline
\end{tabular}




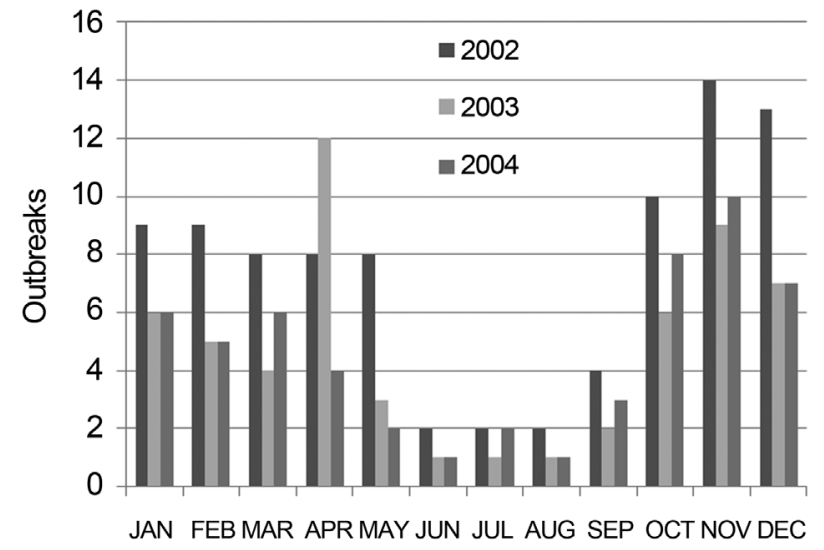

Figure 1 - Monthly ccurrence of outbreaks of Salmonella spp. in the State of Rio Grande do Sul, Brazil, during 2002 to 2004.

ers ageing 10 to 19 years old (18.15\%), as indicated in Table 2. There was no significant difference between the occurrence of salmonelloses between males and females, even though the female group showed a slightly higher incidence $(51.93 \%)$.

Analysing the results of Table 3, it is possible to verify that 256 food vehicles were identified in the 202 salmonellosis outbreaks. These numbers indicate that more than one food vehicle were involved in several outbreaks.

Potato salad with homemade mayonnaise was the most involved preparation in the outbreaks (53.51\%), followed by meat and meat products (roasted beef, roasted chicken, ground beef, raw and cooked beef and minced chicken $-21.48 \%$ ), and pastry products (pies, cakes, lasagna, capeletti and pastels $-16.41 \%$, Table 3 ).

Table 4 indicates that the majority of the outbreaks occurred in private homes $(55.81 \%)$ followed by food services $(12.1 \%)$. If the results of Table 1 and Table 4 were compared, it is possible to note that there is a small differ-
Table 2 - Age and sex of people involved in outbreaks of Salmonella spp. in the State of Rio Grande do Sul, Brazil, during the period of 2002 to 2004.

\begin{tabular}{lccccc}
\hline Age (years) & 2002 & 2003 & 2004 & Total & $\%$ \\
\hline $0-1$ & 4 & 5 & 1 & 10 & 0.24 \\
$1-4$ & 56 & 54 & 24 & 134 & 3.23 \\
$5-9$ & 95 & 109 & 56 & 260 & 6.27 \\
$10-19$ & 314 & 267 & 172 & 753 & 18.15 \\
$20-49$ & 951 & 825 & 574 & 2350 & 56.66 \\
$>50$ & 222 & 229 & 148 & 599 & 14.44 \\
Unknown & 7 & 22 & 13 & 42 & 1.01 \\
Sex & & & & & \\
Male & 762 & 764 & 468 & 1994 & 48.07 \\
Female & 887 & 736 & 531 & 2154 & 51.93 \\
\hline
\end{tabular}

ence between the total numbers of the outbreaks reported (Table 1: 202 and Table 4: 206). This difference can be explained by the occurrence of the same outbreak involving different places after the intake of a common food preparation.

The major factor contributing to the salmonellosis outbreaks was the use of raw materials without sanitary inspection (i.e. eggs, 26.07\%) (Table 5). Other factors responsible for the outbreaks were storage of food at ambient (room) temperate for more than 2 hours $(18.58 \%$ ), improper food manipulation (12.5\%) and improper refrigeration $(9.65 \%)$.

\section{Discussion}

In Brazil, there were 6,349 notifications of foodborne outbreaks during 1999 to 2009, causing 123,917 ill people and 70 deaths. Among those outbreaks, $42.5 \%$ were caused by Salmonella spp. (Brasil, 2010). Contrasting these num-

Table 3 - Food vehicles of outbreaks of Salmonella spp. in the State of Rio Grande do Sul, Brazil, during the period of 2002 to 2004.

\begin{tabular}{|c|c|c|c|c|c|}
\hline \multirow[t]{2}{*}{ Food vehicle } & \multicolumn{3}{|c|}{ Number of outbreaks } & \multicolumn{2}{|c|}{ Total } \\
\hline & 2002 & 2003 & 2004 & $\mathrm{n}$ & $\%$ \\
\hline Salad $^{1}$ with homemade mayonnaise & 56 & 41 & 40 & 137 & 53.51 \\
\hline Pastry products ${ }^{2}$ & 21 & 12 & 9 & 42 & 16.41 \\
\hline Meat and meat products ${ }^{3}$ & 26 & 14 & 15 & 55 & 21.48 \\
\hline Milk and dairy products ${ }^{4}$ & 1 & 0 & 3 & 4 & 1.57 \\
\hline River water & 1 & 2 & 1 & 4 & 1.57 \\
\hline Eggs & 2 & 0 & 1 & 3 & 1.17 \\
\hline Corn & 0 & 0 & 2 & 2 & 0.78 \\
\hline Not identified & 6 & 0 & 3 & 9 & 3.51 \\
\hline Total & 113 & 69 & 74 & 256 & 100 \\
\hline
\end{tabular}

${ }^{1}$ salad of potato, paste, vegetables and others.

${ }^{2}$ pies, cakes, lasagna, capeletti and pastels.

${ }^{3}$ roasted beef, roasted chicken, ground beef, raw and cooked beef and minced chicken.

${ }^{4}$ raw milk, cheese and pudding. 
Table 4 - Place eaten of Salmonella spp. in the State of Rio Grande do Sul, Brazil, during the period of 2002 to 2004.

\begin{tabular}{lccccccc}
\hline \multirow{2}{*}{ Place } & \multicolumn{3}{c}{ Number of outbreaks } & & \multicolumn{2}{c}{ Total } \\
\cline { 2 - 4 } \cline { 7 - 8 } & 2002 & 2003 & 2004 & & $\mathrm{n}$ & $\%$ \\
\hline Private homes & 58 & 29 & 33 & & 120 & 55.81 \\
$\begin{array}{l}\text { Commercial food } \\
\text { establishments }\end{array}$ & 10 & 7 & 8 & & 25 & 12.1 \\
Clubs and associations & 7 & 5 & 4 & & 16 & 8.84 \\
Community rooms & 4 & 8 & 6 & & 18 & 10.7 \\
Schools & 2 & 3 & 1 & & 6 & 2.79 \\
Refectories & 5 & 4 & 3 & & 12 & 5.58 \\
Industrial kitchens & 3 & 3 & 2 & & 8 & 3.72 \\
Others & 1 & 0 & 0 & & 1 & 0.46 \\
Total & 90 & 59 & 57 & & 206 & 100 \\
\hline
\end{tabular}

bers, in the United States, 47.8 million illnesses and three thousand deaths are estimated to occur each year due to foodborne illnesses (Scallan et al., 2011). Of this statistic, 1.4 million cases are estimated to be caused by the primary etiologic agent Salmonella (Voetsch et al., 2004). Even though it is very difficult and may be impossible to compare realities found in countries like Brazil and the United States, it is possible to note a strong difference between the numbers of registered outbreaks in both countries. This difference can be attributed to many factors like differences in the production systems, differences in field operations, consumption patterns, among others, however probable one important factor is the precariousness of surveillance system in many regions of Brazil. Brazil is composed by approximately 195 million people distributed in 27 States. The great majority ( $72 \%$ ) of the Brazilian foodborne notifi- cations have been done by only three States of the Southern Brazil, i. e. RS (30\%), São Paulo (22\%) and Paraná (12\%) (Brasil, 2010). In several States of Brazil, unfortunately, there is a lack of human and financial resources and there is lack of training for the personnel involved in foodborne investigations.

Between 2002 and 2004 in the State of RS, Salmonella was responsible for more than $32 \%$ of the outbreaks notified and investigated by health officers, causing 4,148 ill people, 1,878 hospitalizations and one death. Similar results were showed by Costalunga and Tondo (2002) who had demonstrated that salmonelloses accounted for $36 \%$ of foodborne disease outbreaks investigated in the State of RS between 1997 and 1999 (Costalunga and Tondo, 2002) and by Silveira and Tondo (2006) who had shown that salmonellosis was the first foodborne disease in the State of RS in the period of 2000 to 2001 (Silveira and Tondo, 2006). These results are in agreement with the Brazilian Ministry of Health that has published approximately $35 \%$ of the foodborne outbreaks occurred in Brazil, during 1999 to 2004, ending with laboratory testing, were caused by Salmonella spp. (Carmo et al., 2005).

Other countries also have reported data on salmonelloses. For example, in the period of 1995 to 2000, 35\% of confirmed outbreaks in Australia were caused by Salmonella, of which eight deaths were recorded (Todd, 1997). According to Hughes et al. (2007), in England and Wales in the period of 1992 to 2003, it was found that Salmonella spp. was responsible for $52 \%$ the investigated cases of foodborne outbreaks. The data from Austria, in 2005, showed that Salmonella was the cause of $76 \%$ of the 606 outbreaks (Much et al., 2007) and, in the same year, in France, Salmonella was the leading cause of hospitalization

Table 5 - Factors that contributed to the Salmonella spp. in the State of Rio Grande do Sul, Brazil, during 2002 to 2004.

\begin{tabular}{|c|c|c|c|c|c|}
\hline \multirow[t]{2}{*}{ Factors contributing to the outbreak } & \multicolumn{3}{|c|}{ Number of outbreaks } & \multicolumn{2}{|c|}{ Total } \\
\hline & 2002 & 2003 & 2004 & $\mathrm{n}$ & $\%$ \\
\hline Use of raw material without sanitary inspection & 25 & 24 & 24 & 73 & 26.07 \\
\hline Holding food at ambient (room) temperature for more than 2 hours & 22 & 18 & 12 & 52 & 18.58 \\
\hline Improper hygiene of food handlers & 9 & 14 & 12 & 35 & 12.5 \\
\hline Inadequate refrigeration & 7 & 11 & 9 & 27 & 9.65 \\
\hline Poor hygiene of equipment and utensils & 5 & 8 & 6 & 19 & 6.78 \\
\hline Cross-contamination & 3 & 2 & 4 & 9 & 3.21 \\
\hline Contamination by infected food handler & 3 & 2 & 2 & 7 & 2.5 \\
\hline Improper warm holding & 2 & 1 & & 3 & 1.07 \\
\hline Improper cooking & 1 & 1 & 1 & 3 & 1.07 \\
\hline Ingestion of contaminated water & 1 & 2 & 1 & 4 & 1.44 \\
\hline Improper place of food processing & 1 & & & 1 & 0.35 \\
\hline Use of wood utensils & & & 1 & 1 & 0.35 \\
\hline Unknown & 23 & 4 & 19 & 46 & 16.43 \\
\hline Total & 102 & 87 & 91 & 280 & 100 \\
\hline
\end{tabular}


and death related to foodborne diseases (Vaillant et al., 2005). In China, Salmonella was responsible for $19 \%$ of the outbreaks caused by bacterial contamination at schools during the period of 1994 to 2005 (Wang et al., 2007). These data confirms the importance of this microorganism as aetiological agent in relation to public health issues worldwide.

During the present research, the period with highest salmonelloses occurrence in the State of RS was comprised in springtime, $i$. e. during the months of October, November and December, tending to decrease in subsequent months of summertime. This higher incidence in springtime could be explained by the wide temperature variation during the day-long period in the State of RS, where very often the morning periods present cold temperatures, whilst afternoons are frequently warm or hot. According to Surveillance Service officers of RS, Salmonella outbreaks occur due to the negligence with food temperature control during springtime, when weather temperatures do not seem to be as high, especially in mornings, and people are not concerned about salmonelloses and do not store food in refrigeration. In summertime, the number of salmonellosis outbreaks generally decreases because people store food refrigerated. The subsequent declining number of salmonellosis cases during autumn and winter was a probable consequence of the temperature decline in southern Brazil, where the average temperature is usually around $10^{\circ} \mathrm{Cel}-$ sius. In opposite to the results reported for the State of RS, summer was pointed as the season when the highest amount of salmonellosis outbreaks occurred in Argentina (Caffer and Eiguer, 2004) and in the United States (CDC, 2006).

According to Magnus et al. (1999) Salmonella has no age preference, but generally demonstrates a linear increase in the incidence with increasing age. In the present study the age group most involved in salmonelloses were people above 19 years old $(71.1 \%)$, followed by children and adolescents between 10 and 19 years old $(27.65 \%)$. These results can be explained by the fact that people above 19 years old are those representing the economical active population of the State of RS, which mostly made its food consumptions out of home. However, it is necessary to point out that, according to our results, most of the salmonelloses of the State of RS occurred inside private homes, followed by food services. Similar findings were reported by the Brazilian Ministry of Health during the analysis of outbreaks occurred in 1999 and 2004, demonstrating that the private homes (49\%) followed by commercial food establishments $(19 \%)$ were also the sites of the highest rate of Salmonella outbreaks (Carmo et al., 2005).

According to the results of the present study and those reported in preview ones (Costalunga and Tondo, 2002; Silveira and Tondo, 2006), the high incidence of salmonellosis in the State of RS seems to be related mainly with the consumption of egg and egg products without proper heating. Other studies have reported similar results (FDA,
2010; Humphrey, 1994). Our work demonstrated that the main food vehicle responsible for salmonelloses was the potato salad prepared with homemade mayonnaise, and similar results were reported previously (Costalunga and Tondo, 2002; Silveira and Tondo, 2006). One probable explanation is the fact that, as a cultural habit of RS population, homemade mayonnaise is generally prepared with raw and cooked eggs well mixed with soya oil and warm cooked potato. Very often the eggs used are those produced in small farms or at home without sanitary inspection, increasing the probability of Salmonella contamination. During homemade mayonnaise preparation, Salmonella can easily multiply in eggs due to warm temperature provided by cooked potato and subsequent maintenance in inadequate temperatures (De Paula et al., 2005). However, if eggs or egg products are stored in proper refrigeration temperature (Brasil, 2009; Jay, 2005; Rio Grande do Sul, 2006) and thermal processed-egg yolk are used to prepare homemade mayonnaise the risk of salmonellosis decreases significantly.

In the State of RS, several salmonellosis outbreaks were also caused by pastry products, as pies, cakes, lasagna, capeletti and pastels, and by meat and meat products, as roasted beef, roasted chicken, ground beef, raw and cooked beef and minced chicken. Outbreaks caused by pies and cakes also could be attributed to contaminated eggs used in its preparations, whilst salmonelloses caused by lasagna, capeletti and pastels had Salmonella in their meat fillings. Salmonelloses caused by meat and meat products have been reported in RS by previous studies (Costalunga and Tondo, 2002; Silveira and Tondo, 2006), and most of them can be attributed to meat contamination and crosscontamination during meat products preparation. The fourth food vehicle group most involved with salmoneloses in RS was milk and dairy products, i.e. raw milk and cheeses. The involvement of these kinds of foods with salmonelloses can be explained because some people in RS have the habit of drinking raw milk and others use raw milk to produce a typical cheese called "Colonial cheese". The most common form of production of Colonial cheese involve a maturation period of less than one week and this procedure is not sufficient for the complete inactivation of Salmonella by lactic acid bacteria.

In this study, the two mainly factors that contributed to the outbreaks were the usage of raw material without sanitary inspection (for example, eggs) and holding foods in ambient (room) temperature for more than 2 hours. In fact, probably the most important factor to be controlled is the process temperatures because even contaminated eggs will not cause salmonellosis if they were properly cooked and conserved under refrigerated temperatures. Previous studies have indicated homemade mayonnaise as an important cause of salmonellosis outbreaks in the State of RS. For example, during the period of 1997 to 1999, homemade mayonnaise was responsible for $42.45 \%$ (Costalunga and 
Tondo, 2002) of the salmonellosis cases registered in RS, while in 2000 - 2001 this preparation was responsible for $48.1 \%$ (Silveira and Tondo, 2006) of the cases. Results of the present study demonstrated that homemade mayonnaise was responsible for $53.51 \%$ of the salmonellosis cases, during 2002 to 2004, indicating that the consumption of homemade mayonnaise was an important cause of salmonellosis in the State of RS.

During the period of 1999 to 2009, the consumption of eggs was identified as the main cause for most of the salmonellosis outbreaks (22.8\%) investigated in Brazil (Brasil, 2010). In United States, egg was the food most frequently involved in outbreaks of Salmonella spp. reported by the Centers for Disease Control and Prevention (CDC) (2009). Similar results have been reported by several other researchers, as Greig and Ravel (Greig and Ravel, 2009), Hughes et al. (2007) and Much et al. (2007).

Microorganisms such as Salmonella, mainly $S$. Enteritidis, can infect the ovaries and oviducts of chickens, thus contaminating eggs, especially during shell formation. In addition, egg shells can be contaminated with intestinal bacteria during the passage through the chicken cloaca (Forsythe, 2010). Foods prepared with eggs were involved in $72 \%$ of Salmonella outbreaks investigated in the State of RS in 2000 (Nadvorny et al., 2004). It is important to note that the multiplication of Salmonella can be prevented by adequate cooling of foods. According to Malheiros et al. (2007), in a study carried out in order to investigate the growth kinetics of different serovars of Salmonella in homemade mayonnaise there was not detected growth of any Salmonella serovars in homemade mayonnaise stored at $9.5^{\circ} \mathrm{C}$ in the first 24 hours. However, $S$. Enteritidis SE86 showed higher counts in the first 6 hours when cultivated at $30{ }^{\circ} \mathrm{C}$.

Other studies investigating the strains of Salmonella involved with foodborne outbreaks in RS have reported interesting information about these food pathogens. For example, Geimba et al. (2004) have shown that more than $97 \%$ of the salmonelloses occurred in the State of RS, during 1999 to 2002, were caused by $S$. Enteritidis. Studies with those $S$. Enteritidis isolates have shown that the majority of the outbreaks were caused by one specific strain of $S$. Enteritidis called SE86. (Oliveira et al., 2006).Giving sequence to these studies, Oliveira et al. (2007) used molecular methods in order to compare $S$. Enteritidis strains isolated from stool cultures of salmonellosis victims with $S$. Enteritidis strains isolated from food involved with the outbreaks occurred in RS from 1999 to 2006, and showed that SE86 was involved in most of them. Even though, different Salmonella serovars been isolated from diverse types of foods in RS, the majority of the foodborne outbreaks from 1999 to 2006 has been caused by S. Enteritidis SE86 (Oliveira et al., 2007).

The results of the present study demonstrated the need for greater attention in food safety issues related to salmonellosis. The fact that most of the Salmonella outbreaks have occurred inside private homes followed by food services indicates the need for public campaigns aiming awareness and more rigid regulatory control, mainly concerning temperature control, usage of foods after sanitary inspection and appropriate food handling.

\section{Acknowledgments}

We would like to thanks to the staff of Water and Food Microbiology Laboratory of FEPPS/LACEN/RS and to all the Staff of Secretary of Health of Rio Grande do Sul, especially to the M. Sc. Josete Balaiardi Silveira and the Veterinarians Susana Costalunga Lima and Denise Maria da Silva Figueiredo, who greatly works to improve regional Surveillance and Epidemiological Services of the State of RS.

\section{References}

Brasil. Ministério da Saúde. Coordenação de Vigilância das Doenças de Transmissão Hídrica, Alimentar e Sexual. Manual integrado de prevenção e controle de doenças transmitidas por alimentos. [Brasília, DF, 2001].

Brasil. Ministério da Saúde. Agência Nacional de Vigilância Sanitária. Resolução RDC 35 de 17 de junho de 2009. Ovos Instruções de conservação e consumo. Diário Oficial [da República Federativa do Brasil], Brasília, 18 de jun. 2009. Seção 1.

Brasil. Ministério da Saúde. Secretaria de Vigilância em SaúdeSVS. Manual Integrado de Prevenção e Controle de Doenças Transmitidas Por Alimentos. 2010. Disponível em: http://portal.saude.gov.br/portal/arquivos/pdf/manual_dta.pdf. Accessed 1 Aug 2010.

Caffer MI, Eiguer T (2004) Salmonella Enteritidis in Argentina. International Journal of Food Microbiology 21:15-19.

Carmo GMI, Oliveira AA, Dimech CP, Santos DA, Almeida MG, Berto LH, Alves RM, Carmo EH (2005) Vigilância epidemiológica das doenças transmitidas por alimentos no Brasil, 1999-2004. Boletim Eletrônico Epidemiológico 6:1-7. http://portal.saude.gov.br/portal/arquivos/pdf/bol_epi_6_2005_corrigido.pdf.

Centers For Disease Control And Prevention (CDC) 2006 Surveillance for foodborne-disease outbreaks - United States, 1998-2002. Appendix B - Guidelines for confirmation of foodborne-disease outbreaks. CDC Surveillance Summaries, MMWK, 55(SS10); 1-34.

Centers for Disease Control and Prevention (CDC) FoodNet 2007. Surveillance Report. Atlanta: U.S. Department of Health and Human Services, 2009.

Costalunga S, Tondo EC (2002) Salmonellosis in Rio Grande do Sul, Brazil, 1997 to 1999. Brazilian Journal of Microbiology 33:342-346.

De Paula, CMD, Mariot, RF, Tondo EC (2005) Thermal inactivation of Salmonella enteritidis by boiling and frying egg methods. Journal of Food Safety 25:43-57.

FDA - Food And Drug Administration. Salmonella Enteritidis Outbreak in Shell Eggs. 2010. Available: http://www.fda.gov/Food/NewsEvents/WhatsNewinFood/u cm222684.htm. Accessed 17 Aug 2010. 
Forsythe SJ (2010) The microbiology of safe food. WileyBlackwell, United Kingdom, UK.

Geimba MP, Tondo EC, Oliveira FA, Canal CW, Brandelli A (2004) Serological characterization and prevalence of spvR genes in Salmonella sp. isolated from foods involved in foodborne outbreaks occurred in Rio Grande do Sul, south of Brazil. Journal of Food Protection 67:1229-1233.

Greig JD, Ravel A (2009) Analysis of foodborne outbreak data reported internationally for source attribution, International Journal of Food Microbiology 130:77-87.

Hughes C, Gillespie IA, O'Brien SJ (2007) Foodborne transmission of infectious intestinal disease in England and Wales, 1992-2003. Food Control 18:766-72.

Humphrey TJ (1994) Contamination of egg shell and contents with Salmonella enteritidis: a review. International Journal of Food Microbiology 21:31-40.

Jay J (2005) Microbiologia de Alimentos. Ed. ArtMed, Porto Alegre.

Laconha I, Baggesen DL, Rementeria A, Garaizar J (2000) Genotypic characterization by PFGE of Salmonella enterica serotype Enteritidis phage type 1, 4, 6 and 8 isolated from animal and human sources in three European countries. Veterinary Microbiology 75:155-165.

Lindqvist R, Andersson Y, Jong B, Norberg P (2000) A summary of reported foodborne disease incidents in Sweden, 1992 to 1997. Journal of Food Protection 63:1315-1320.

Magnus SA, Hambleton IR, Moosdeen F, Serjeant GR (1999) Recurrent infections in homozygous sickle cell disease. Arch Dis Child 80:537-41.

Malheiros PS, De Paula CMD, Tondo EC (2007) Growth kinetics of Salmonella Enteritidis involved in outbreaks of foodborne illness in Rio Grande do Sul, southern Brazil: a comparison with other serovar strains. Ciência Tecnologia de Alimentos 27:751-755.

Mead PS, Slutsker L, Dietz V (1999) Food-related illness and death in the United States. Emerg Infect Dis 5:607-625.

Much P, Pichler J, Allerberger F (2007) Foodborne infectious outbreaks, Austria 2005. Wien Klin Wochenschr 119:150-7.

Mürmann L, Santos MC Longaray SM, Both JMC, Cardoso M (2008) Quantification and molecular characterization of Salmonella isolated from food samples involved in salmonellosis outbreaks in Rio Grande do Sul, Brazil. Brazilian Journal of Microbiology 39:529-534.

Nadvorny A, Figueiredo DMS, Schmidt V (2004) Ocorrência de Salmonella sp. em surtos de doenças transmitidas por alimentos no Rio Grande do Sul em 2000. Acta Scientiae Veterinariae 32:47-51.

Notermans S, Hoogenboom-Verdegaal AH (1992) Existing and emerging foodborne diseases. International Journal of Food Microbiology 15:197-205.
Oliveira FA, Frazzon, APG, Brandelli A, Tondo EC (2007) Use of PCR-ribotyping, RAPD, and antimicrobial resistance for typing of Salmonella enteritidis involved in food-borne outbreaks in Southern Brazil. Journal of Infection in Developing Countries 1:170-176.

Oliveira FA, Brandelli A, Tondo EC (2006) Antimicrobial resistance in Salmonella Enteritidis from foods involved in human salmonellosis outbreaks in southern Brazil. The New Microbiologica 29:49-5.

Peresi JTM, Almeida IAZC, Lima SI, Marques DF, Rodrigues EC A, Fernandes SA, Gelli DS, Irino K (1998) Surtos de enfermidades transmitidas por alimentos causados por Salmonella Enteritidis. Revista de Saúde Pública 32:477-483.

Rio Grande do Sul. Secretaria Estadual da Saúde. Divisão de Vigilância Sanitária. Relatórios anuais de DTA. Porto Alegre, 2001 (não paginada).

Rio Grande do Sul. Secretaria Estadual da Saúde. Centro Estadual de Vigilância em Saúde. Rede Estadual de Análise e Divulgação de Indicadores para a Saúde. 2006. A saúde da população do Estado do Rio Grande do Sul, 2005. CEVS, Porto Alegre, 183 pp.

Roadford SA, Board RG (1993) Review: fate of pathogens in home-made mayonnaise and related products. Food Microbiology 10:269-278.

Scallan E, Griffin PM, Angulo FJ, Tauxe R, Hoekstra RM Foodborne illness acquired in the United States - Unspecified agents. Emerging Infectious Diseases, www.cdc.gov/eid, v. 17, n. 1, January 2011.

Silveira JB, Tondo EC (2006) Salmonellosis outbreaks occured in Rio Grande do Sul, Southern Brazil, during 2000 to 2001. International Symposium Salmonella and salmonellosis. Epidemiology and Public Health. Saint Malo, France, pp. 521-522.

Todd EC (1997) Epidemiology of foodborne diseases: a worldwide review. World Health Stat Q 50:30-50.

Vaillant V, Valk H, Baron E, Ancelle T, Colin P, Delmas MC (2005) Foodborne Infections in France. Foodborne Pathogens and Disease 2:221-32.

Voetsch AC, VanGilder TJ, Angulo FJ (2004) FoodNet estimate of the burden of illness caused by nontyphoidal Salmonella infections in the United States. Clin Infect Dis 38:127-34.

Wang S, Duan H, Zhang W, Li JW (2007) Analysis of bacterial foodborne disease outbreaks in China between 1994 and 2005. FEMS Immunol Med Microbiol 51:8-13.

Tondo EC, Ritter AC, (2012) Salmonella and Salmonellosis in Southern Brazil: a review of the last decade. In: Salmonella: Classification, Genetics and Disease outbreaks, Monte A.S., De Santos P.E. (eds) Nova Science Publishers, Inc. New York, pp 175-191.

All the content of the journal, except where otherwise noted, is licensed under a Creative Commons License CC BY-NC. 